This article has been accepted for publication in Higher Education Research \& Development, published by Taylor \& Francis." 


\title{
I don't need peer support: effective tutoring in blended learning environments for part-time, adult learners
}

\author{
Andrew Youde \\ Department of Education and Community Studies, The University of Huddersfield, \\ Huddersfield, United Kingdom \\ Corresponding author: Email a.youde@hud.ac.uk \\ Andrew Youde is the Acting Head of Department (Education and Community Studies) at The \\ University of Huddersfield. His research interests include online tutors and tutoring, adult \\ learners, emotional intelligence, and blended and distance learning environments.
}




\title{
I don't need peer support: effective tutoring in blended learning environments for part-time, adult learners
}

\author{
Given the rise of social media engagement within society, there are challenges \\ for tutors in blended and online contexts to provide opportunities for social \\ constructivist learning experiences within their institutional learning \\ environments. This article proposes a module approach to teaching, learning and \\ assessment for learners undertaking part-time, vocationally related degrees. A \\ mixed methods approach was adopted to conduct a detailed exploration of eight \\ tutors' practice with data gathered from three principal sources. Interviews with \\ tutors explored their approaches to delivery and considered factors that impacted \\ on quality; students' perceptions of their learning experiences were assessed \\ using an attitude survey; an analysis of the content and communications in the \\ virtual learning environment provided insight into tutors' online practice. \\ Analysis of modules suggested limited online peer-to-peer interaction with tutors \\ noting the difficulties of promoting engagement. The article argues for a \\ constructivist approach in this context with a need for tutors to promote a simple \\ module structure, focused around assessment, that creates space for learning. \\ This structure appeared appropriate for these learners, enabling them to manage \\ the influence of daily events, together with pressures and time constraints of \\ work. Further, available tutor support together with assessment as the focus of \\ learner activities outside face-to-face contexts, were associated with module \\ success. The findings could aid tutors in designing and delivering courses for \\ similar groups of learners.
}

Keywords: blended learning, blended tutoring, constructivism, adult learners, heutagogy.

\section{Introduction}

This article reports outcomes from a study into effective tutors and tutoring within a higher education (HE), blended learning environment and proposes a module approach to teaching, learning and assessment in this context. The aims of the research included:

- to understand effective practice of tutors in blended learning environments; 
- to evaluate tutors' approaches to teaching, learning and assessment through analysis of their learners' perceptions.

Blended learning typically involves significant online teaching, learning and support, but includes some face-to-face contact (De George-Walker \& Keeffe, 2010). The research involved a detailed exploration of eight tutors' practices on one of their modules, which formed approximately $6 \%$ of a learner's degree. The learners were studying part-time (PT), vocationally relevant degrees whilst, usually, in full-time (FT) employment. There can be difficulties when tutoring these learners, particularly regarding the pressures and time constraints of work (Holley \& Oliver, 2010). However, adult learners tend to understand what they want to achieve from education and have clearer goals in mind (Knowles, Holton, \& Swanson, 2015).

Adults' motivations for study are multifaceted, with both intrinsic and extrinsic motivators found to positively influence adult learner achievement in HE (Feinstein, Anderson, Hammond, Jamieson, \& Woodley, 2007; Swain \& Hammond, 2011). Intrinsic motives relate to the interest and enjoyment experienced from engaging in study (Swain \& Hammond, 2011), whilst extrinsic motives for those undertaking vocationally relevant courses include increasing promotional opportunities (Feinstein et al., 2007). Research suggests (Bailey \& Card, 2009; Murphy, Shelley, White, \& Baumann, 2011) that tutors should incorporate extrinsic motivators such as providing an appropriately structured knowledge base, having clear learning goals, and allowing learners to build on previous learning.

Smith and Hill's (2019) review of blended learning found flexibility, personalisation, enhanced learner outcomes, and the development of autonomy and selfdirected learning as key benefits. A further benefit cited was increased interaction, however, little empirical support was provided of the educational value of peer-to-peer 
interaction (p.7). Boelens, Wever and Voet (2017), in their review of blended learning environment design, cite stimulating interaction as a key challenge. The 20 studies reviewed as part of their research generally support the benefits of face-to-face elements, with some also highlighting the value of tutor-peer interaction. However, none of these studies reported effective peer-to-peer interaction within the online elements of blended learning environments. Social constructivist models of e-learning have commonly promoted opportunities for peer interaction within online, formal, university learning environments (Salmon, 2011; Garrison \& Kanuka, 2004), however, it would appear that such interaction is challenging for tutors and of little benefit for learners. De George-Walker and Keeffe's (2010, p. 12) case study suggested that "successful learners are aware of their learning and situational needs and preferences and are able to select learning formats to fit their changing needs", indicating autonomy and self-direction as noted above, which could be a factor in why students appear not to value online peer-to-peer interaction.

Research exploring the experiences and outcomes of part-time, adult learners on blended learning programmes is scant. Ausburn's (2004) study explored the course design elements most valued by adult learners in blended learning environments, which comprised those containing options, personalization, self-direction, variety, and a learning community. McDonald (2014) noted the importance of adaptable learning and found all learners valued interaction, both in online and face-to-face elements. These two studies emphasise the value of interaction and a learning community for adult learners and provide a contrast with Smith and Hill's (2019) and Boelens and colleagues' findings regarding the challenge of stimulating peer-to-peer interaction within online environments. It is these contrasting findings that this article seeks to explore. 
There has been little evidence of theory advancement within educational technology research (Halverson, Graham, Spring, Drysdale, \& Henrie, 2014; Hew, Lan, Tang, Jia, \& Lo, 2019) and in blended learning environments (Smith \& Hill, 2019, p. 9), and this article proposes such a model for these learners together with an effective approach to teaching, learning and assessment that appear to influence learner perceptions of quality.

\section{Research context}

\section{Local context}

The research is based at a "new' ${ }^{1}$ university in the north of England, which has approximately 540 full-time academic staff and 22,000 students. The courses investigated were all within an education disciplinary area. Therefore, the research focussed on this particular subject area to explore effective blended learning practice through this disciplinary lens. The courses used a day-school model of delivery, where learners typically attend classes one day per month with the remaining time spent studying independently and utilising resources and communication tools held on the University virtual learning environment (VLE). Modules are usually one term in length (approximately three to four months) from the first day-school until learners submit summative assessments. Each module, therefore, has two or three day-schools with the overall course structure and delivery models developed by tutors and course leaders in conjunction with course approval committees. Tutors have responsibility for teaching, assessment and monitoring learner progress, and for preparing suitable learning

\footnotetext{
${ }^{1}$ Higher Education in the UK was changed in 1992 when a new group of institutions were given the name 'university'. These post-1992 universities are former polytechnics or colleges of higher education.
} 
materials for both online contexts and day-schools, but can structure the delivery as they wish.

\section{Learning in the digital Age}

Social media are becoming increasing integral to student learning as a mechanism for communicating with both peers and extended networks. This is facilitated by both technology convergence, where devices and software are getting better at sharing usergenerated content, and by ubiquitous connections, either via wifi or mobile networks. Building on this context, Wheeler (2015) argues that learners are now more selfdirected, particularly given the proliferation of open access resources and usergenerated information. Personal (or professional) learning networks (PLNs), informal networks of people with whom a student interacts to support aspects of learning for their degree studies, influence student study (see Casquero, Ovelar, Romo, Benito, \& Alberdi, 2016; Dabbagh \& Kitsantas, 2012). These include, but are not restricted to, colleagues at work, fellow degree students, family, friends, or relative strangers connected to through online forums. Siemens (2005) assertion that "formal education no longer comprises the majority of our learning. Learning now occurs in a variety of ways - through communities of practice, personal networks, and through completion of work-related tasks", appears relevant for those undertaking PT, vocationally relevant degrees.

\section{Conceptual framework}

This section firstly justifies the use of Mayes and de Freitas' (2007) theoretical perspectives as the conceptual framework to explore tutor practices on their modules. It then moves to introduce learner self-direction and self-determinism, to justify the use of 
Heutagogical principles (Kenyon \& Hase, 2013) to further explore effective practice in a technology-rich, external learning environment.

For effective teaching and learning in HE, Biggs' (2003) Constructive Alignment Model states that all components of teaching and learning should be congruent or aligned, an approach that is significant in underpinning course design (Ruge, Tokede, \& Tivendale, 2019). Mayes and de Freitas (2007) developed this model for online and blended learning contexts. They proposed three broad theoretical perspectives, which are:

- The associationist/empiricist perspective (learning as activity);

- The constructivist perspective ${ }^{2}$ (learning as achieving understanding through individual or social approaches);

- The situative perspective (learning as social practice).

Mayes and de Freitas (2007, p. 20) state, "most implementations of e-learning will include blended elements that emphasise all three levels: learning as behaviour, learning as the construction of knowledge and meaning, and learning as social practice", and this was found in the modules investigated as part of the research.

The constructivist perspective has both an individual and social focus to allow learning as achieving understanding in both individual and collaborative contexts (Mayes \& de Freitas 2007). Fox (2001, p. 31) argues that it is important for tutors to realise students are always trying to make sense of their study in terms of what they already know. This was relevant for the learners in the research study who were trying

\footnotetext{
${ }^{2}$ Mayes and de Freitas (2007) originally termed this the cognitive perspective, but this has since been developed in the course of work in e-learning and pedagogy funded by JISC.
} 
to apply their study to work practices. The learners were professionals and brought a breadth of existing knowledge, understanding and experiences to the classroom (Fox, 2001, p. 29), highlighting the relevance of analysing the data in relation to constructivist learning theory.

The Individual Constructivist Perspective (IPC) highlights the achievement of understanding through active discovery, where learners construct new ideas by hypothesis testing. The pedagogy aligning with this perspective includes interactive environments for knowledge expansion, cognitive scaffolding, experimentation with the discovery of principles, adaptation of teaching to existing student understanding, and support for reflection, analysis and evaluation. Assessment strategies aligning with this perspective encourage experiential learning, experimental learning, problem-based learning, case-based learning and self-evaluation, and autonomy in learning.

The Social Constructivist Perspective (SCP) highlights the achievement of understanding through collaboration and dialogue. The pedagogy aligning with this perspective includes interactive and collaborative environments leading to conceptual development; support for reflection, peer review and evaluation; and experimentation with shared discovery. Assessments aligning with this perspective are common to the ICP, however, include collaborative activities, participation, peer review and shared responsibility.

This research undertakes a holistic examination of a tutor's approach to the delivery of a module so Mayes \& de Freitas' perspectives provide a coherent framework to evaluate practices across the unit of study. In addition, as Ausburn (2004) points out, self-direction is a blended learning course design element valued by adult learners. However, adults often want to be passive in the learning process (Knowles et al., 2015), but treating them in such a manner can cause tensions considering their need for self- 
direction. The theory of Heutagogy is relevant here, defined as 'self-determined learning', which includes a focus on what the learner wants to learn, and not what is taught (Kenyon \& Hase, 2013, p. 7). There has been renewed interest in this theory since Web 2.0 emerged coupled with the increased access to online resources and networks (Blaschke, 2012), and is therefore relevant to the technology rich educational context. Both constructivist and andragogy principles and practices influenced the theory's development and it is relevant for professional and lifelong learners (Blaschke, 2012; Coetzee, 2014), therefore an important consideration for this research study. A key attribute of andragogy is self-directed learning, which indicates some structure to the learning environment and tutor involvement in the choice of study. However, Heutogogy extends this view by promoting the notions of leaner self-determination of study that include a non-linear design and learning approach (Anderson, 2016; Blaschke, 2012). A tutor's role within this approach is to guide learners' interactions with various resources, both online and in networks, to solve work-related problems (Anderson, 2016). Within an Heutagogical approach, learners are more active in the process - and not passive, they develop skills in becoming self-directing, and tend to be more satisfied given they are driving the study (Kenyon \& Hase, 2013, p. 14).

Wheeler (2015, p. 39) notes that Heutagogy and the conceptualisation of selfdetermined learning embrace both formal and informal education contexts. When exploring vocational learning, both informal and formal dimensions of learning are copresent (Manuti, Pastore, Scardigno, Giancaspro \& Morciano, 2015), indicating the complexity of designing blended learning courses within the digital age. However, Kenyon and Hase (2013, p. 8) cite an example of Heutagogy within a formal HE context. Here the learner has:

- a guided choice of topic; 
- a guided approach to the proposed learning;

- agreement on reporting progress;

- agreement on the content and method of final assessment.

These principles provide a practical distinction between the concepts of self-direction and self-determinism for adult learners within blended environments. They are adopted within this study as a further lens to explore effective tutor practices within a technology-rich external environment.

\section{Methodology}

An explanatory mixed methods design (Creswell \& Plano Clark, 2007, p. 71) was adopted to conduct a detailed exploration of tutors' practice. This firstly involved issuing a questionnaire to ascertain learners' perceptions of tutors, and the teaching, learning and assessment they experienced. Qualitative analysis followed, via tutor interviews and VLE content analysis, which explored approaches to teaching and learning appearing to influence learner perceptions. The tutor sampling criteria applied were:

- their learners were studying qualifications relevant to their profession;

- they delivered the module on a 'day school' basis, that is, where learners attend university for a small number of days, with remaining teaching conducted via computer-mediated communications (CMCs);

- they were experienced teachers/lecturers (over five years) and had delivered at least three previous modules in blended learning contexts;

- their learners were studying undergraduate or post-graduate courses on a parttime basis. 
The British Educational Research Association's (BERA) Revised Ethical Guidelines for Educational Research (2011) informed the ethical considerations of this research, particularly regarding participant consent and University agreement to undertake this study. Participant privacy was supported by selecting tutor pseudonyms based on popular UK names.

A random selection of students $\left(n=72^{3}, 64 \%\right.$ response rate, covering the eight modules investigated) completed the questionnaire, which was designed to elicit general opinion about the quality of tutoring they experienced. To obtain this, a modified version of the Course Experience Questionnaire (CEQ) was used (Ramsden, 1991). The original questionnaire was designed as an indicator of teacher effectiveness on courses in HE institutions and draws on learners' perceptions of teaching, curriculum and assessment. It was originally designed for courses with traditional approaches to teaching with a more regular tutor/learner contact than blended models of delivery allow. It was modified to make it suitable for an individual tutor (see Kreber, 2003) and a blended teaching model (see Richardson, 2009). The scale items ${ }^{4}$ adopted for this research were largely the same as the original CEQ, but adapted in line with Kreber's (2003) and Richardson's (2009) studies, and were:

- good teaching communication;

- good teaching feedback on, and concern for, student learning;

${ }^{3}$ Comprised of 60 female and 12 male respondents, which is in line with the gender balance commonly occurring on the courses investigated within education disciplinary areas.

${ }^{4}$ The scale item 'appropriate assessment' was included in the questionnaire in line with the original CEQ and the modified versions cited. However, it was removed from the analysis following an unacceptable score on a reliability test. 
- clear goals and standards;

- appropriate workload.

Descriptive statistics generated from the questionnaire provided a broad overview of learner perceptions and a ranking of tutors, which then allowed the qualitative data to explain and build upon the initial quantitative results.

Qualitative data was gathered from interviews with tutors, which explored their approaches to delivery and factors that impacted on quality, and an analysis of the content and communications in the VLE, which provided insight into their online practice. Template analysis was chosen to analyse both the tutor interview data and VLE communications (King, 2004). King (2004, p. 256) argues that template analysis is not a single method or research itself, or a methodological position, but a series of techniques for the inductive analysis of textual data. A template is a list of codes that are added and modified as the researcher interprets the data and is organised to represent emerging themes. The first template had a mix of descriptive codes, such as tutor experience, and analytical codes, for example, tutor ability to work within available resources. Flexibility was required in its development and subsequent analysis, particularly as themes were developing around tutors' approaches appearing to align with learner feedback. Themes were noted as the coding process was undertaken and were analysed using a framework approach to thematic analysis (Bryman, 2008, p. 550), which involved tabulating emerging ideas against tutors (who were ranked in descending order of learner perceptions, measured by CEQ scores). Through this process, themes emerged that were important in all modules; important in those of tutors receiving the higher CEQ scores; and those that were only observable in the tutors receiving lower scores. 
Data collection for this article occurred between March and July, 2011, however, the student groups investigated are representative of cohorts, particularly regarding gender and age, found within education disciplines, generally, today. As a result, research for this group is still relevant.

\section{Findings}

\section{Introduction}

This section begins with an overview of tutor CEQ scores, which provided insight into learner perceptions and indicated their broad satisfaction whilst studying the modules under investigation. Tutors' approaches to teaching, assessment and support are then analysed to explore this apparent learner satisfaction.

\section{Tutor CEQ scores}

The CEQ provided feedback about tutor effectiveness on modules and measured learner perceptions of teaching and assessment. Learners gave answers to five-point Likert scale questions, with the results detailed in Table 1.

\begin{tabular}{|l|l|l|l|l|l|l|}
\hline Tutor & N & CEQ Total & $\begin{array}{l}\text { Clear } \\
\text { Goals and } \\
\text { (Pseudonym) }\end{array}$ & $\begin{array}{l}\text { Good Teaching } \\
\text { Communication }\end{array}$ & $\begin{array}{l}\text { Good } \\
\text { Teaching } \\
\text { Standards }\end{array}$ & Workload \\
\hline
\end{tabular}




\begin{tabular}{|l|c|c|c|c|c|c|}
\hline Ann & 6 & $4.06(0.36)$ & $4.29(0.40)$ & $4.50(0.35)$ & $4.25(0.45)$ & $3.71(0.68)$ \\
Bill & 7 & $3.86(0.64)$ & $3.96(1.09)$ & $4.33(0.69)$ & $3.93(0.72)$ & $3.89(0.66)$ \\
Claire & 7 & $4.10(0.35)$ & $4.29(0.57)$ & $4.62(0.36)$ & $3.64(0.35)$ & $4.25(0.64)$ \\
Daisy & 4 & $3.23(0.45)$ & $3.69(0.24)$ & $3.58(0.74)$ & $2.87(1.18)$ & $2.94(0.31)$ \\
Emily & 15 & $3.99(0.26)$ & $4.42(0.28)$ & $4.15(0.44)$ & $4.12(0.44)$ & $3.48(0.47)$ \\
Frank & 5 & $3.43(0.37)$ & $3.45(0.62)$ & $4.00(0.97)$ & $3.30(0.67)$ & $2.90(0.88)$ \\
George & 14 & $3.55(0.40)$ & $3.59(0.74)$ & $4.31(0.53)$ & $3.68(0.56)$ & $2.99(0.55)$ \\
Harry & 14 & $3.42(0.67)$ & $3.42(1.15)$ & $3.55(1.06)$ & $3.13(0.80)$ & $3.46(0.47)$ \\
\hline Mean & & $3.72(0.53)$ & $3.89(0.83)$ & $4.12(0.79)$ & $3.73(0.77)$ & $3.38(0.63)$ \\
\hline
\end{tabular}

Table 1. Tutor's CEQ Results - Mean and (Standard Deviation).

Preliminary analysis revealed a CEQ mean total of 3.72 and similar high scores were evident across the constituent scales, indicating learners considered their tutors were effective. For a five-point scale, relatively small standard deviations were found, which suggested a common perception from the groups of learners. Overall module pass rates were found to be greater than $95 \%$, with some of the remaining $5 \%$ expected to complete in the near future. Learners were asked to rate their module achievement on a five-point scale (very disappointed to very good) and the resultant mean score was 3.83 indicating broad satisfaction with their results and academic development. During the interviews, when tutors were asked to provide an overall impression of their groups, there was a consensus around motivated learners, engaged in their study, and producing good quality work. This could be expected given their choice to study PT, however, overall, these indicators, together with the generally high CEQ scores received, suggest successful modules with students learning, engaging and achieving. The following section unpicks this key finding. 


\section{Tutors' approaches to teaching, learning, assessment and learner support}

\section{Introduction}

Limited tutor-peer and peer-to-peer interaction was found within the online elements of all modules, therefore, when describing their teaching, tutors talked about practices occurring at day schools. The section firstly analyses the teaching occurring on the modules before moving on to discuss assessment and, then, learner support.

\section{Teaching}

All tutors described taking a facilitative approach at day schools, developed around a range of student-centred activities, showing evidence of 'teaching as facilitating understanding on the part of the student' and 'teaching as an interaction between the teacher and student' (Kember, 1997, p. 264). Both individual and group activities were common to each module with tutors stressing student-centred approaches. George spoke about learners' "active participation” at day schools with Bill's comment also illustrative of a facilitative approach:

\footnotetext{
Very quickly I will get into 'what is action research'? We have a discussion about what it is, we agree the characteristics, and will then get into some social learning, group work.
}

How tutors positioned themselves in relation to their learners further pointed to a facilitative approach. Four tutors described themselves as 'facilitators' with two further emphasising support for learners in applying theory and recognised good practice to work contexts. A further two tutors, Ann and Daisy, described their learners as the "experts", which, again, emphasised the role of facilitator.

These student-centred activities were supplemented with some instruction, including both 'teaching as imparting information' and 'teaching as transmitting 
structured knowledge' (Kember, 1997, p. 264), where understanding of key information, theory and concepts was required. For her module 'Education and the Law', Ann outlined, “I do specific delivery on equal opportunities, the new equality bill to make sure they were up to speed on that". Daisy, when discussing her teaching of equality and diversity, stated, "I do tend to do a fair bit of input into areas that I think they need to know about", with this including key legislation in the area. Both examples were illustrative of transmission of information and all tutors described some instruction of key module information such as submission dates and assessment requirements.

Tutors described three broad reasons for the lack of engagement and learner collaboration within online environments, namely negative student experiences on previous modules; VLE access and user issues; and time for tutors to develop and manage online activities. However, tutors' previous learning experiences in online contexts could have been influential. Ann and George noted difficulties in encouraging engagement when this had not been required or encouraged in previous modules and reported learners' feelings of frustration at the prescribed nature of collaboration. Ann stated:

This is the last module of a three-year programme, and they hadn't engaged particularly well with discussions online and I don't think that would have been a time to start with that... When asked about the Blackboard [University VLE] element, a lot of them said they didn't like it, they were not comfortable with online. (Ann).

Learners informed Emily and Harry that the VLE was "clunky", slow and impersonal, and reported access issues. These issues were often found to be user error when investigated with Harry noting “it's just they haven't got that confidence to give it a whirl or they're looking in the wrong module", but this point did overlap with the third 
issue of time, which was a concern for three tutors. The day school model was described to be pressured with Harry stating there was limited time to orientate learners around the VLE content and tools. He outlined that some had not developed effective use of the VLE in course inductions. This was a barrier to learning, and a particular problem, as his learners were still in the first year of study within HE. Further, Daisy and George, who received lower CEQ scores, stated they did not have sufficient time to effectively set up and manage pedagogically appropriate opportunities for online engagement and collaboration. Daisy commented:

I think I could have done more. I have tried over the year, bits with different groups and now because I think it is a time issue as well, I don't have time to change everything and also with having a few new modules to teach this year.

Both tutors cited time as a factor underpinning the level and quality of online interaction. Arguably, such feelings of frustration are likely to influence learners' perceptions of the module if tutors are making reference, albeit subtly, to the time available for delivery.

All tutors had previously undertaken study in either online or blended contexts with each reporting negative learning experiences. They outlined limited engagement with peers in online environments with reasons given including time, superficial discussions, contributions a "tick-box exercise" (George), and a lack of trust that would have developed in face-to-face meetings. Further, four tutors (Ann, Claire, Daisy, Frank) found the online elements impersonal and lacking human contact. Such negative perceptions of learning in this context could have influenced their module delivery.

\section{Assessment}

Day schools commonly included activities that aided assignment preparation, with this continuing outside day schools via computer-mediated communications (CMCs) (see 
Table 2 for a summary of tutors' interaction with learners via CMCs during their modules). In all modules, learners had autonomy to direct their learning and focus on assignment work, with tutors available for support. Ann and Claire, who received the highest CEQ scores, were (to quote Ann) "there on demand" to facilitate learners' application and analysis within work contexts. Whilst being available to learners was common to all, other tutors tried to engage learners in a variety of online activities, but with limited success. Claire used discussion boards to provide feedback on assignment plans. However, minimal peer interaction was occurring via this medium. Emily described regular synchronous web conferences, which had predetermined topics to discuss. Whilst these were successful in engaging learners and allowing peer interaction, the tutor explained that more practical issues were discussed around assessment and use of wider university systems. She noted the use of such software was new to her and further work was required to appropriately structure sessions. Bill encouraged the use of wikis to allow collaboration with peers to validate assignment choices, but described limited learner engagement. Two other tutors, George and Harry, encouraged the submission of assignment plans on VLE discussion boards, which was generally carried out. However, there were minimal comments from peers and VLE analysis revealed none from the tutors. From analysis of activities outside day schools, module assessments were the key driver of student learning with these undertaken independently from peers, but with support from tutors.

\begin{tabular}{|l|l|}
\hline Tutor & $\begin{array}{l}\text { Summary of tutors' interaction with learners via CMCs during their } \\
\text { modules }\end{array}$ \\
\hline Ann & E-mail support. \\
\hline Bill & E-mail support, wiki to validate learner assignment plans. \\
\hline
\end{tabular}




\begin{tabular}{|l|l|}
\hline Claire & $\begin{array}{l}\text { E-mail support, learner assignment plans discussed on VLE discussion } \\
\text { boards. }\end{array}$ \\
\hline Daisy & E-mail support. \\
\hline Emily & $\begin{array}{l}\text { E-mail support, online synchronous conferences, established a group on a } \\
\text { social networking site to aid induction and learner socialisation. }\end{array}$ \\
\hline Frank & E-mail support. \\
\hline George & $\begin{array}{l}\text { E-mail support, learner assignment plans added to VLE discussion } \\
\text { boards. }\end{array}$ \\
\hline Harry & $\begin{array}{l}\text { E-mail support, learner assignment plans added to VLE discussion } \\
\text { boards. }\end{array}$ \\
\hline
\end{tabular}

Table 2. - Summary of tutors' interaction with learners via CMCs during their modules.

High scores received on the CEQ scale Clear Goals and Standards (mean $=3.89$ ) suggested learners knew what was expected and why they were studying a particular topic, with tutors indicating the relevance of activities at day schools. Bill was illustrative of all tutors here when outlining "what's in it for me" to learners, as activities and assignments were introduced. Learners had choice over assignment focus, and all were related to practice within their organisations. Assignments were problembased and generally case-method within learners' organisations, with examples being action research, analysis of a piece of legislation in context, and an evaluation of leadership and management structures.

All modules were structured around assessment strategies and this appeared appropriate for the needs of adult learners undertaking vocationally relevant degrees. This was evidenced from tutor comments during the interviews and analysis of VLE content, particularly module assessment guides. Modules included extensive formative assessment that involved review of an assignment plan and feedback on parts of draft 
assignments. Dates were established for each aspect of assessment and were generally structured around day schools, assignment plans being submitted at the second day school, for example. As stated above, all learners had choice over assignment focus and all were related to practice within their organisations. These two factors led all tutors to teach key principles but then allow learner contextualisation, principally through module assessment requirements. Ann was illustrative here when stating "the problem with a topic such as 'education and the law' is, depending on where the students were, there is no way we could put everything on a VLE or teach it at day schools", and this forced tutors into an assessment driven structure. Ann developed this point further when stating:

\footnotetext{
When the day schools were finished one of the first things I would do is go through the assessment...... and say right what I would like you to do before the next time I see you....... I would really like to see your case studies so I can begin formative feedback.
}

This was a common approach to structure modules around assessment requirements and appeared appropriate for learners, who are likely to be managing the competing pressures of work and family life. This structure enabled the spread of workload across a module, but was strengthened with tutor feedback throughout the assessment process. Clear goals and standards were apparent from the above module structure, but also within detailed assessment briefs and, in a number of cases, use of exemplar material. George noted the motivational value of plans and exemplar work: ...that makes them feel better about doing things. They also like the idea about having a past example so that certainly helps motivate them. 
This, again, indicated a common approach from tutors regarding an assessment driven structure to modules and the motivational effects that assessment briefs were described to have. This common structure was enhanced with timely and constructive feedback.

\section{Learner support}

The findings suggested PT, blended courses need to be flexible in terms of meeting learning outcomes, but have sufficient structure in their delivery for learners with competing pressures from work and family life. Research (Stubbs, Martin \& Endlar, 2006) shows that to sustain the chosen teaching, learning and assessment, effective student support strategies need to be embedded within the programme structure. Whilst module design was centred around assessment strategies, active management of support, predominantly facilitated by e-mail, was described by tutors. Differing approaches to the provision of learner support, and the extent and nature of online learning activities, appeared to be factors in the differing tutor CEQ scores.

Five tutors, receiving the higher CEQ scores, outlined similar proactive strategies to support and encourage learners in meeting the formative and summative assessment requirements of modules. Formative assessment processes were monitored closely with e-mail, phone calls or "quick chats at day schools" (Claire) used to prompt learners and encourage dialogue. Emily's module required completion of a number of 'mini-projects' and she outlined monitoring learners' engagement and would "chase them up", if they were not in touch.

Common across all modules was learner support through feedback on formative assessments. This included feedback on assignment plans and draft reports. All tutors emphasised commitment to supporting learners through assessments, which was demonstrated through response times. Emily illustrated this when stating, 'the response times were really good this year, often in the morning that it arrived'. These learners 
appear to require a minimum level of support, which involves timely and constructive feedback to formative assessments, however, tutors receiving higher CEQ scores were more proactive in communicating. This was exemplified by Ann when stating:

I don't know if I am soft but when I tutor with blended [learning], I do regularly send students emails and try to keep regular contact and I also make it very clear that it is their responsibility to actually contact me.

Whilst illustrating a high level of support this comment highlights the expectations of tutor and learner roles set throughout the module and the value of e-mail in blended learning.

Student support mechanisms appeared most effective when facilitated by e-mail and not by other forms of computer-mediated communications (CMCs), such as wikis and discussion boards. Whilst this may be expected given e-mail's requirement of a personal response there appeared to be other factors influencing learner perceptions. The two tutors receiving the highest CEQ scores, Ann and Claire, both spoke enthusiastically about being available for learners, sending e-mails to check on progress and responding in a timely manner. They described such use of e-mail as motivating for learners. Similar feedback was received from other tutors about the value of e-mail in prompting and encouraging learners, however, other communication media, such as wikis and discussion boards, were less effective. In each case, contributions were not part of the summative mark received for the module and limited learner engagement was evident. This discussion suggests that learners prefer e-mail as a communication medium supported by a facilitative tutor. Learners could be engaged with their personal learning networks (PLNs) rather than the media suggested by module tutors. Or, for those adopting an instrumental approach to their studies, e-mail could provide the quickest and easiest support mechanism to successfully pass the module. An approach 
to teaching, learning and assessment is now proposed that appears suitable for both these groups of adult learners.

\section{Discussion}

From the research outlined in the previous section, a module approach to teaching, learning, assessment and support for learners undertaking part-time (PT), vocational degrees is now presented. Constructivist models of e-learning predominantly promote opportunities for peer interaction within formal, online university learning

environments. However, research into blended learning practices has repeatedly found such interaction challenging and ineffectual (Boelens, Wever \& Voet, 2017; Smith \& Hill, 2019) and this study concurs with this position. Given the rise of social media engagement within society (Dabbagh \& Kitsantas, 2012) and the use of personal learning networks (PLNs) (Wheeler, 2015), there are challenges for tutors in blended and online contexts to provide such opportunities for social constructivist learning experiences. As a result, an alternative approach for a social media rich external environment is outlined that considers the needs of adult learners, particularly around their potential desire for self-directed study.

An important part of the module success was the congruent nature of teaching, learning and assessment. The common approach outlined shows alignment with the Individual Constructivist Perspective (ICP) (Mayes \& de Freitas, 2007), which appears appropriate for learners studying PT, vocationally relevant degrees at a distance. The perspective highlights the achievement of active discovery where learners construct new ideas through hypothesis testing, with this apparent from the 'facilitative' teaching style adopted by all tutors at day schools, but was further evidenced through the problembased and case-method assessments common to all modules. The extent of learners working independently, particularly on module assessments, outside day schools, 
resonates with individual constructivism as it was student-centred, whilst encouraging experimentation and application of theory to practice. Clear goals and standards were apparent in detailed assessment briefs and exemplar materials, with modules generally structured around assessment requirements, both formative and summative. Such a module structure appears appropriate for adult learners undertaking vocationally relevant degrees, whilst managing the influence of daily events, together with the pressures and time constraints of work. Further, having tutor support available, with assessment the focus of learner activities outside day schools, was associated with module success. It, potentially, provides space for learners to engage with external networks that could be supporting their vocationally related assessments.

This approach to teaching provides some structure and tutor facilitation, hence supporting adults in making the transition from dependent to self-directing learners (Knowles et al., 2015). However, there is scope for them to be responsible for their decisions on education (Knowles et al., 2015). This was particularly evident in learners having choice over assessment focus, with assignment work rooted in work problems, and their ability to work independently between face-to-face sessions. When considering Kenyon and Hase's (2013, p. 8) Heutagogical approach within a HE context, there were commonalities with the effective teaching suggested by an ICP approach, particularly around notions of a guided choice of topic, a guided approach to the proposed learning, and agreement on reporting progress. However, learners had no choice in the method of final assessment, which was dictated by the University.

In today's social media rich society, an Individual Constructivist Perspective approach (Mayes \& de Freitas, 2007) could allow time for learners to draw on their own learning networks (Wheeler, 2015). It allows self-direction and a non-linear approach to learning, as suggested by Heutagogy, and access to a wealth of resources on the 
internet and in networks. Further, this approach provides some structure and support for learners, which can help mitigate Wheeler's $(2015$, p. 40) concern regarding the quality, reliability and provenance of content of information found in such environments. The tutor's role in developing both digital literacies and traditional academic skills, such as evaluating a source's validity, appear vital when adopting this teaching approach.

Although this is small-scale research focussed solely within an education disciplinary area, it has found that the ICP provides a relevant theoretical base as relevant for these particular learners in this blended learning context. Although Mayes and de Freitas' (2007) perspective lacks a strong empirical base, its development from existing teaching and learning theory, namely Biggs' (2003) Constructive Alignment Model, strengthens the perspective's value.

An interesting finding from this research is learners' motivations for undertaking study and the effect this could have had on their engagement with tutors and peers on the modules. Instrumental motives, such as promotional opportunities, could be influencing both their choice of, and approach to, study. The research found e-mail was a common communication medium and this level of tutor support would be the easiest and quickest method for an instrumental learner to successfully complete a module to a standard of their satisfaction. More intrinsically motivated learners could be engaged in discussions, debates and sharing learning experiences within their PLNs. Significantly, whether learners adopted an intrinsic or instrumental approach to study, they did not engage in peer collaboration within the formal confines of their HE module.

\section{Acknowledgments}

I wish to thank Professor Kevin Orr and Professor Lyn Tett for their helpful comments on an earlier version of this article. 


\section{References}

Anderson, T. (2016). Theories for learning with emerging technologies. In G. Veletsianos (Ed.), Emergence and innovation in digital learning: Foundations and applications (pp. 35-50). Edmonton, Canada: Athabasca University Press.

Ausburn, L.J. (2004). Course design elements most valued by adult learners in blended online education environments: An American perspective. Educational Media International, 41, 327-337. doi: 10.1080/0952398042000314820

Bailey, C.J., \& Card, K.A. (2009). Effective pedagogical practices for online teaching: Perception of experienced instructors. Internet and Higher Education, 12(3-4), 152-155. doi: 10.1016/j.iheduc.2009.08

BERA. (2011). Ethical guidelines for educational research. Nottingham: British Educational Research Association.

Biggs, J. (2003). Teaching for quality learning at university ( $2^{\text {nd }}$ ed.). Maidenhead: Open University Press.

Blaschke, L.M. (2012). Heutagogy and lifelong learning: A review of heutagogical practice and self-determined learning. The International Review of Research in Open and Distributed Learning, 13(1), 56-71. doi: 10.19173/irrodl.v13i1.1076

Boelens, R., De Wever, B., \& Voet, M. (2017). Four key challenges to the design of blended learning: A systematic literature review. Educational Research Review, 22, 1-18. doi: 10.1016/j.edurev.2017.06.001

Bryman, A. (2004). Social research methods ( $3^{\text {rd }}$ ed.). Oxford: Oxford University Press.

Casquero, O., Ovelar, R., Romo, J., Benito, M., \& Alberdi, M. (2016). Students' personal networks in virtual and personal learning environments: A case study in higher education using learning analytics approach. Interactive Learning Environments, 24(1), 49-67. doi: 10.1080/10494820.2013.817441

Coetzee, M. (2014). Exploring the mediating role of graduate attributes in relation to academic self-directedness in open distance learning. Higher Education Research \& Development, 33(6), 1085-1098. doi: $10.1080 / 07294360.2014 .911260$

Creswell, J.W., \& Plano Clark, V.L. (2007). Designing and conducting mixed methods research. London: Sage Publications.

Dabbagh, N., \& Kitsantas, A. (2012). Personal learning environments, social media, and self-regulated learning: A natural formula for connecting formal and informal 
learning. Internet and Higher Education, 15(1), 3-8. doi:

10.1016/j.iheduc.2011.06.002

De George-Walker, L., \& Keeffe, M. (2010). Self-determined blended learning: A case study of blended learning design. Higher Education Research \& Development, 29(1), 1-13. doi: 10.1080/07294360903277380

Feinstein, L., Anderson, T.M., Hammond, C., Jamieson, A., \& Woodley, A. (2007). The social and economic benefits of part-time, mature study at Birkbeck College and the Open University. Milton Keynes: Open University.

Fox, R. (2001). Constructivism examined. Oxford Review of Education, 27(1), 23-35. doi: $10.1080 / 03054980125310$

Garrison, D.R., \& Kanuka, H. (2004). Blended learning: Uncovering its transformative potential in higher education. The Internet and Higher Education, 7, 95-105. doi: 10.1016/j.iheduc.2004.02.001

Halverson, L.R., Graham, C.R., Spring, K.J., Drysdale, J.S., \& Henrie, C.R. (2014). A thematic analysis of the most highly cited scholarship in the first decade of blended learning research. The Internet and Higher Education, 20, 20-34. doi: 10.1016/j.iheduc.2013.09.004

Hew, K.F., Lan, M., Tang, Y., Jia, C., \& Lo, C.K. (2019). Where is the "theory" within the field of educational technology research? British Journal of Educational Technology, 50(3), 956-971. doi: 10.111/bjet.12770

Holley, D., \& Oliver, M. (2010). Student engagement and blended learning: Portraits of risk. Computers \& Education, 54, 693-700. doi: 10.1016/j.compedu.2009.08.035

Kember, D. (1997). A reconceptualisation of the research into university academics' conceptions of teaching. Learning and Instruction, 7(3), 255-275. doi: 10.1016/S0959-4752(96)00028-X

Kenyon, C., \& Hase, S. (2013). Heutagogy fundamentals. In S. Hase \& C. Kenyon (Eds.), Self-determined learning: Heutagogy in action (pp. 7-18). London: Bloomsbury.

King, N. (2004). Using templates in the thematic analysis of text. In C. Cassell \& G. Symon (Eds.), Essential guide to qualitative methods in organisational research (pp. 256-271). London: Sage Publications. 
Knowles, M.S., Holton, E.F., \& Swanson, R.A. (2015). The adult learner: The definitive classic in adult education and human resource development ( $8^{\text {th }} \mathrm{ed}$.). Oxford: Routledge.

Kreber, C. (2003). The relationship between students' course perception and their approaches to studying in undergraduate science courses: A Canadian experience. Higher Education Research and Development, 22, 57-70. doi: $10.1080 / 0729436032000058623$

Manuti, A., Pastore, S., Scardigno, A.F., Giancaspro, M.L., \& Morciano, D. (2015). Formal and informal learning in the workplace: a research review. International Journal of Training and Development, 19(1), 1-17. doi: 10.1111/ijtd.12044

Mayes. T., \& de Freitas, S. (2007). Learning and e-learning: the role of theory. In H. Beetham \& R. Sharpe (Eds.), Rethinking pedagogy for a digital age: Designing and delivering e-learning (pp. 13-25). Abingdon, Oxfordshire: Routledge.

McDonald, P.L. (2014). Variation in adult learners' experiences of blended learning in higher education. In A.G. Picciano, C.D. Dziuban \& C.R. Graham (Eds.), Blended learning: Research perspectives (pp. 215-234). New York: Routledge.

Murphy, L.M., Shelley, M.A., White, C.J., \& Baumann, U. (2011). Tutor and student perceptions of what makes an effective distance language teacher. Distance Education, 32(3), 397-419. doi: 10.1080/01587919.2011.610290

Ramsden, P. (1991). A performance indicator of teaching quality in higher education: The Course Experience Questionnaire. Studies in Higher Education, 16, 129150. doi: 10.1080/03075079112331382944

Richardson, J.T.E. (2009). The attainment and experiences of disabled students in distance education. Distance Education, 30(1), 87-102. doi: $10.1080 / 01587910902845931$

Ruge, G., Tokede, O., \& Tivendale, L. (2019). Implementing constructive alignment in higher education-cross-institutional perspectives from Australia. Higher Education Research \& Development, 38(4), 833-848. doi: 10.1080/07294360.2019.1586842

Salmon, G. (2011). E-moderating: The key to teaching \& learning online ( $3^{\text {rd }} \mathrm{ed}$.). London: RoutledgeFalmer. 
Siemens, G. (2005). Connectivism: A learning theory for the digital age. Instructional Technology \& Distance Learning, 2(1). Retrieved from http://www.itdl.org/journal/jan_05/article01.htm

Smith, K., \& Hill. J. (2019). Defining the nature of blended learning through its depiction in current research. Higher Education Research \& Development. 38(2), 383-397. doi: 10.1080/07294360.2018.1517732

Stubbs, M., Martin, I., \& Endlar, L., (2006). The structuration of blended learning: Putting holistic design principles into practice. British Journal of Educational Technology, 37(2), 163-175. doi: 10.1111/j.1467-8535.2006.00530.x

Swain, J., \& Hammond, C. (2011). The motivations and outcomes of studying for parttime mature students in higher education. International Journal of Lifelong Education, 30(5), 591-612. doi: 10.1080/02601370.2011.579736

Wheeler, S. (2015). Learning with 'e's. Carmarthen: Crown House Publishing. 